\title{
9
}

Carlos Gómez García*

\section{PLAN INTEGRADO DE PROMOCIÓN DE ALIMENTOS Y VINOS EN EL MERCADO CANADIENSE}

Los alimentos y bebidas son uno de los rubros principales de las exportaciones españolas a Canadá y cuentan con una estrategia de apoyo bien definida por parte de la Administración comercial española. El objetivo de este artículo es presentar la estrategia que viene desarrollando ICEX en colaboración con la Oficina Económica y Comercial de España en Toronto en el mercado canadiense para impulsar las ventas del sector de la agroalimentación. Las actuaciones promocionales y de apoyo a la empresa se articulan en una estrategia integral que se ha denominado Plan Integrado de Promoción de Alimentos y Vinos. Este plan cuenta con cuatro programas que abarcan desde el inicio del proceso de acceso al mercado hasta el establecimiento de planes sectoriales por producto. Así, se pueden distinguir los siguientes programas: Programa de Acceso al Mercado, Programa de Consolidación y Expansión del Mercado, Programa de Gastronomía y Programa de Planes Sectoriales.

Palabras clave: Plan Integrado de Promoción de Alimentos y Vinos, acceso al mercado, consolidación y expansión, Plan de Vinos en Canadá, Plan de Cítricos en Canadá.

Clasificación JEL: O51, Q18.

\section{Introducción}

El comportamiento de nuestras ventas de productos agroalimentarios en el mercado canadiense está siendo muy favorable en los últimos años. En el Cuadro 1 se muestra el crecimiento continuado de las importaciones que Canadá ha realizado desde España en los últimos diez años.

$\mathrm{Si}$, para evitar la distorsión en la evolución de nuestras ventas al mercado canadiense

\footnotetext{
* Consejero Económico y Comercial Jefe de la Oficina Económica y Comercial de España en Toronto.

Versión de agosto de 2021.

DOI: https://doi.org/10.32796/bice.2021.3140.7281
}

causada por la COVID-19, consideramos el periodo 2011-2019, podemos concluir que las exportaciones españolas de productos agroalimentarios se han más que triplicado, creciendo un $12,5 \%$ durante el último año del periodo (2018-2019), hasta alcanzar un valor de casi 437 millones de dólares canadienses. Los datos muestran una tendencia de crecimiento positiva y continuada, por encima de la media del mercado y también de los principales competidores de España. Esta tendencia se ha visto frenada en 2020 debido a la pandemia provocada por la COVID-19, pero es previsible que, una vez superada la misma, volvamos a retomar la senda de crecimiento anterior. 
CUADRO 1

PRINCIPALES PAÍSES EXPORTADORES DE PRODUCTOS AGROALIMENTARIOS A CANADÁ, PARA EL PERIODO 2011-2020*

(En millones de dólares canadienses)

\begin{tabular}{|c|c|c|c|c|c|c|c|c|c|c|c|}
\hline & País & 2011 & 2012 & 2013 & 2014 & 2015 & 2016 & 2017 & 2018 & 2019 & 2020 \\
\hline 1 & Estados Unidos ........ & 15.349.892 & 16.748 .281 & 17.855 .213 & 19.606 .904 & 21.943 .793 & 22.129 .006 & 21.716 .635 & 22.035.139 & 22.534 .825 & 22.835 .467 \\
\hline 2 & México & 1.131 .536 & 1.177 .028 & 1.397 .426 & 1.677 .148 & 1.908 .257 & 2.214 .991 & 2.447 .260 & 2.483.246 & 2.808 .676 & 2.840 .764 \\
\hline 3 & China & 984.574 & 1.018 .763 & 1.032 .778 & 1.149 .349 & 1.279 .773 & 1.397 .775 & 1.444 .249 & 1.474 .128 & 1.552 .831 & 1.533 .579 \\
\hline 4 & Brasil. & 1.023 .251 & 890.139 & 761.312 & 844.843 & 801.534 & 965.383 & 977.553 & 934.625 & 763.663 & 906.808 \\
\hline 5 & Italia . & 391.583 & 393.649 & 433.259 & 472.889 & 513.571 & 588.548 & 627.212 & 709.813 & 699.664 & 802.134 \\
\hline 6 & Tailandia . & 645.836 & 659.352 & 631.366 & 629.783 & 705.786 & 711.470 & 713.654 & 717.838 & 762.321 & 733.528 \\
\hline 7 & India. & 273.738 & 292.557 & 346.314 & 448.600 & 511.767 & 461.287 & 576.483 & 603.964 & 617.161 & 680.519 \\
\hline 8 & Chile ... & 549.106 & 557.520 & 638.408 & 637.655 & 629.106 & 628.493 & 596.758 & 702.145 & 669.191 & 675.035 \\
\hline 9 & Perú ... & 227.477 & 243.079 & 249.592 & 337.907 & 385.074 & 421.921 & 465.646 & 474.161 & 538.469 & 629.870 \\
\hline 10 & Vietnam ... & 231.267 & 241.617 & 305.559 & 435.766 & 471.621 & 484.719 & 526.564 & 576.249 & 571.441 & 608.002 \\
\hline 11 & Guatemala .. & 355.393 & 360.160 & 308.539 & 376.988 & 440.470 & 572.714 & 522.275 & 532.603 & 580.918 & 581.272 \\
\hline 12 & España & 126.426 & 129.962 & 130.419 & 218.319 & 253.519 & 290.503 & 324.316 & 388.313 & 436.758 & 461.874 \\
\hline 13 & Colombia ............ & 326.560 & 266.109 & 252.413 & 320.667 & 342.813 & 343.130 & 406.389 & 380.929 & 380.418 & 432.980 \\
\hline 14 & Nueva Zelanda ......... & 278.359 & 243.696 & 215.710 & 272.031 & 359.256 & 317.566 & 366.486 & 367.299 & 396.642 & 424.795 \\
\hline \multirow[t]{2}{*}{15} & Francia & 199.872 & 185.543 & 205.073 & 214.993 & 230.629 & 251.845 & 271.779 & 318.026 & 340.499 & 362.434 \\
\hline & Total . & 25.935 .639 & 27.303 .096 & 28.989 .009 & 32.524 .571 & 36.356 .491 & 37.539 .978 & 37.838 .751 & 38.865 .922 & 40.384 .255 & 41.602 .841 \\
\hline
\end{tabular}

Respecto a la posición que España ocupa en el ranking de exportadores a Canadá, esta sigue mejorando. En 2013 ocupábamos el puesto 27 ; en 2017, el número 14 , y hemos pasado a ocupar la posición número 12 en el año 2020.

Como mostraremos más adelante, las ventas de vino español en el mercado canadiense han tenido también un comportamiento muy satisfactorio. La exportación de vinos se ha venido consolidando y alcanza cuotas de mercado cada vez más importantes.

Los alimentos y bebidas se erigen, por tanto, en uno de los rubros principales de las ventas españolas en Canadá y cuentan con una estrategia de apoyo bien definida por parte de la Administración comercial española.

El objetivo de este artículo es presentar la estrategia que viene desarrollando ICEX en colaboración con la Oficina Económica y Comercial de España en Toronto en el mercado canadiense para impulsar las ventas del sector de la agroalimentación. Nos ceñiremos, por tanto, a las actividades de apoyo a las empresas o subsectores que se realizan en el mercado de destino de nuestras exportaciones.

Presentaremos, seguidamente, los distintos elementos que componen la promoción agroalimentaria en el mercado canadiense y que se estructuran bajo el denominado Plan Integrado de Promoción de Alimentos y Vinos.

\section{Plan Integrado de Promoción de Alimentos y Vinos}

Varios de los subsectores de la industria agroalimentaria han sido destacados por la Secretaría de Estado de Comercio dentro de su estrategia PASE (Países con Actuación Sectorial Estratégica) diseñada para el mercado canadiense. En concreto, se consideran estratégicos: el sector hortofrutícola fresco; los $D$ 
productos transformados propios de la despensa española, tales como el aceite, las aceitunas, los quesos artesanales, el jamón y los embutidos; y los vinos con denominación de origen.

Lo anterior no excluye la existencia de oportunidades comerciales a nivel empresarial en otros sectores de la industria de alimentación y bebidas.

Existen buenas razones para justificar una actuación sectorial estratégica de impulso al sector de alimentación y bebidas en el mercado canadiense. Entre ellas mencionamos:

- La oportunidad de aprovechar la tendencia favorable de las ventas de productos agroalimentarios españoles. Como se ha señalado antes, se observa un aumento continuado de nuestras exportaciones en alimentos y vino. En particular, algunos productos como el aceite de oliva o el queso han mostrado tasas de crecimiento muy elevadas en los últimos años, con crecimientos de más de un $300 \%$ y un $171 \%$, respectivamente, entre 2016 y 2020 . Esto supone que España se acerca cada vez más a sus competidores europeos en la exportación de productos agroalimentarios a Canadá. En el caso del aceite de oliva virgen extra, por ejemplo, España se erigió en 2020 en el segundo suministrador, solo detrás de Italia. También se ha constatado una reciente proliferación de restaurantes de temática española, siendo la mayoría de ellos de gama media-alta y reconocidos por la prensa especializada.

- La actitud receptiva del consumidor canadiense. El consumidor canadiense no se encuentra completamente familiarizado con nuestros productos, pero gracias al carácter multicultural de las grandes ciudades, es un público abierto a probar nuevos alimentos, sobre todo con la promoción adecuada, mediante degustaciones en puntos de venta y publicaciones especializadas. Asimismo, el aumento de la preocupación por la salud y una alimentación adecuada beneficia a España, en tanto que es paladín de la dieta mediterránea.

Todo ello unido a la décima mayor renta per cápita del mundo, en torno a 43.000 dólares estadounidenses, según datos del Banco Mundial, que permite la consolidación de un segmento gourmet, donde los productos españoles tienen buena acogida.

- La aprobación del CETA como oportunidad. Con la reciente implantación del primer acuerdo de libre comercio entre la Unión Europea y Canadá (CETA), gran cantidad de productos europeos van a ser muy competitivos en el mercado canadiense debido a la eliminación de la mayoría de los aranceles y al aumento de las cuotas en determinados productos. Esto permite que se agilicen los trámites de importación y que crezca el interés de importadores y distribuidores por buscar nuevos clientes europeos.

La actuación promocional y de apoyo a la empresa que desarrolla ICEX en colaboración con la Oficina Económica y Comercial de España en Toronto en el mercado de alimentación y bebidas canadiense articula las distintas iniciativas en una estrategia integral que se ha denominado Plan Integrado de Promoción de Alimentos y Vinos.

Este plan cuenta con cuatro programas concatenados que abarcan desde el inicio del $\square$ 


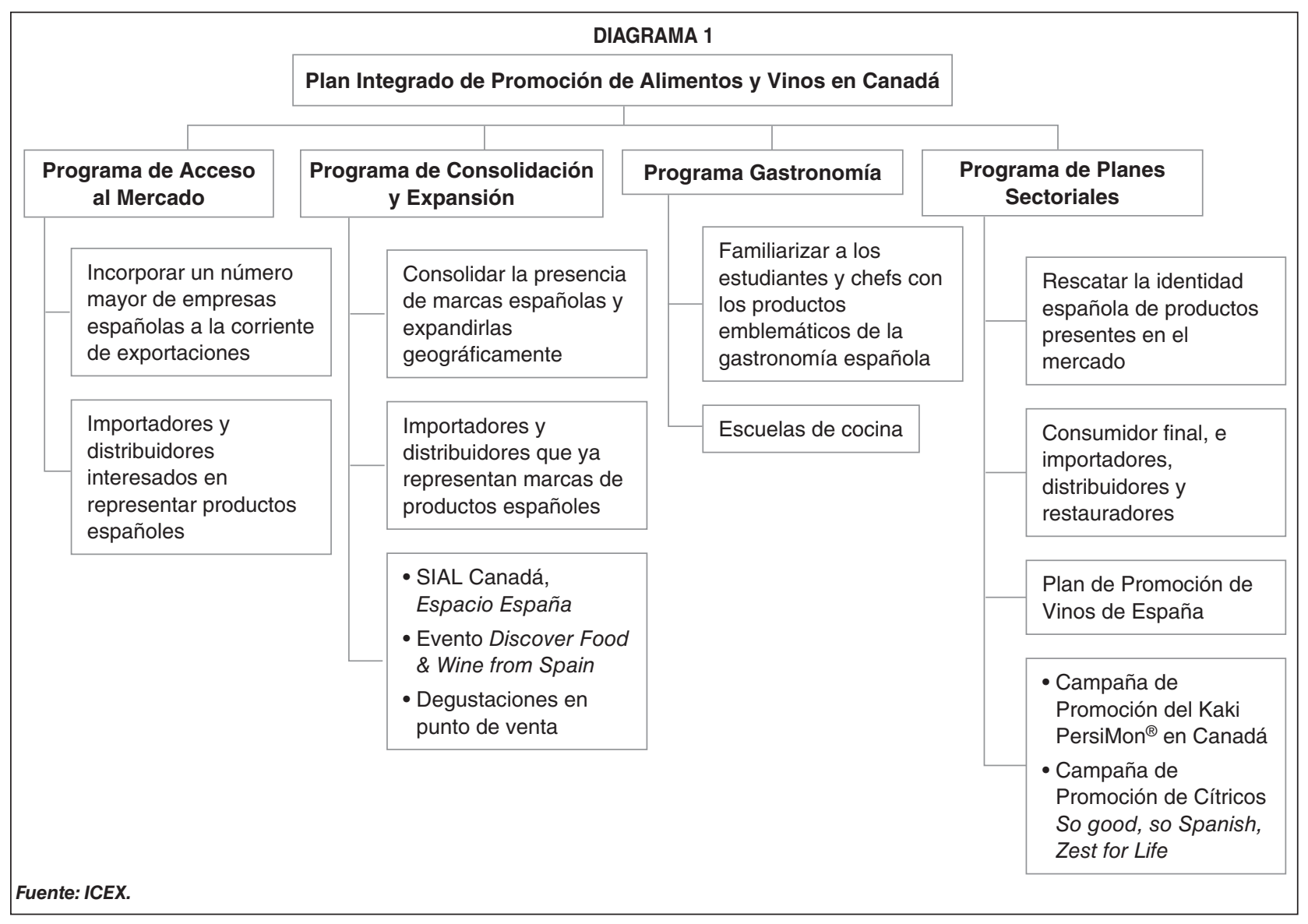

proceso de acceso al mercado hasta el establecimiento de planes sectoriales por producto. Así, se pueden distinguir los siguientes programas:

- Programa de Acceso al Mercado.

- Programa de Consolidación y Expansión del Mercado.

- Programa de Gastronomía.

- Programa de Planes Sectoriales.

El Diagrama 1 que vemos más arriba resume de forma ilustrada las distintas piezas que componen el Plan Integrado. Se indica para cada programa sus principales objetivos, las audiencias a las que se dirige y algunos ejemplos de acciones a emprender.

El resultado que se pretende con esta estrategia es diseñar una estructura compacta de apoyo que facilite la coordinación de las distintas actividades, permita aprovechar sinergias promocionales y pueda encajar nuevas iniciativas de apoyo a la empresa y a los distintos subsectores agroalimentarios. Se desarrollan a continuación cada uno de los programas de apoyo antes referidos.

\subsection{Programa de Acceso al Mercado}

El Programa de Acceso al Mercado pretende coadyuvar a que un número mayor de empresas españolas del sector de la alimentación y bebidas se incorporen a la corriente de exportaciones a Canadá. Va dirigido a las empresas españolas que hayan mostrado por primera vez interés en el mercado canadiense, o que hayan realizado algún acercamiento y aún no tengan un distribuidor establecido en el país. $\triangleright$ 
El objetivo del programa es que las empresas españolas consigan importador o distribuidor en Canadá. Para ello cuenta con una batería de servicios que permiten acompañar a la empresa a lo largo de todo el proceso de acceso al mercado. Estos servicios van desde la información general sobre el mercado y las barreras de acceso al mismo, pasando por el asesoramiento personalizado sobre los canales de distribución más apropiados, la identificación de los importadores y distribuidores más adecuados al producto de la empresa, hasta la organización de eventos que permitan a las empresas españolas entrar en contacto directo con los posibles importadores y distribuidores de sus productos.

En un mercado tan maduro como el canadiense, el contacto entre el exportador español y su potencial importador o distribuidor debe propiciarse en un entorno que genere suficiente interés para el operador canadiense. Por ello, el Programa de Acceso al Mercado apuesta por la organización de dos grandes eventos: la participación bajo pabellón español en la feria agroalimentaria SIAL y la presentación agrupada de empresas dentro del espacio Taste of Spain en el Grocery Innovation Show. Ambos eventos fueron temporalmente suspendidos en 2020 y 2021 debido a la COVID-19, pero la intención es volver a retomarlos en 2022. Estas iniciativas se complementan con un servicio personalizado de identificación de socios comerciales que permite perfilar a los importadores y distribuidores más adecuados para el producto de la empresa española. Este servicio a la empresa, aunque está disponible permanentemente, está especialmente indicado para reforzar la presencia de la empresa en los eventos antes indicados.

SIAL Canadá es la feria más importante del sector agroalimentario en Canadá. Se trata de una feria internacional enfocada fundamentalmente a productos de gama alta. En ella se dan cita productores, importadores y distribuidores del sector agroalimentario. La feria se celebra de manera alternativa en Toronto y Montreal. Para hacer más atractiva la presencia de los distintos expositores en el pabellón español organizado por ICEX, esta se refuerza con un espacio gastronómico denominado Espacio España.

El Espacio España es una zona acotada, diferenciada y acondicionada al efecto dentro del pabellón España, en la que se desarrolla una agenda de actividades de promoción muy atractiva que incluye seminarios, catas, demostraciones culinarias, etc. Todas estas actividades van dirigidas a un público profesional que es invitado para cada sesión de forma específica y diferenciada. El Espacio España permite atraer más visitantes hacia el pabellón español, desarrollar actividades de networking y reforzar la imagen del producto español en su conjunto.

Existen, sin embargo, numerosas empresas españolas cuyos productos no se ajustan al perfil de la feria SIAL y que pueden encontrar acomodo en el Grocery Innovation Show.

El Grocery Innovation Show es el acontecimiento ferial más importante de la distribución de alimentos en Canadá. Tiene, por tanto, un carácter nacional. El evento está organizado por la Federación de Supermercados Independientes de Canadá (entidad que agrupa a los supermercados franquiciados de las grandes cadenas, los distribuidores independientes de las grandes superficies y las cadenas de tiendas denominadas «tiendas de conveniencia»). Tiene dos vertientes anuales: una en Vancouver (abril) y otra (la más importante) en Toronto (octubre) en el Palacio de Congresos de esta ciudad. 
En este evento exponen todas las grandes marcas nacionales y estadounidenses que fabrican o producen alimentos de las categorías básicas de las grandes cadenas de supermercados. Se presentan las novedades que se verán en los lineales de supermercados de la próxima temporada, y los productos expuestos van desde los básicos de la alimentación como lácteos y panadería hasta los más sofisticados que van agregándose a la dieta básica del consumidor canadiense. A este certamen acuden fundamentalmente tiendas de comestibles $y$ supermercados ( $43 \%$ de los visitantes) y cadenas de supermercados (39\%). Aunque menos relevante, también es destacable la presencia de panaderías, tiendas de descuento y tiendas de conveniencia.

El Grocery Innovation Show está inmerso en un rápido proceso de evolución, siguiendo las pautas del mercado canadiense, que tiende hacia la sofisticación de sus productos. Las categorías de lineal van desde los más básicos, como son hamburguesas, yogures y donuts, hasta otros productos de pasta, salsas y platos precocinados, y donde se nota una clara tendencia de evolución hacia aquellos productos de la dieta mediterránea.

La oferta española se presenta agrupada bajo el amparo del concepto Taste of Spain, que incluye rubros de alimentación dirigidos a supermercados y grandes superficies como jugos, alimentos preparados, productos de panadería, productos de café y té, golosinas, enlatados de pescado, vegetales congelados, etc.

El objetivo de Taste of Spain es organizar una acción complementaria a SIAL, aunque de menor alcance, que dé una oportunidad a todas esas empresas que quieren acceder al mercado canadiense, pero que no ven a SIAL como la solución adecuada.
Las Misiones de compradores canadienses a España es otro de los instrumentos tradicionales de apoyo a las empresas en su estrategia de acceso al mercado. Este instrumento se ha visto limitado en los últimos años debido a la pandemia causada por la COVID-19, pero es seguro que se retomará cuando las circunstancias lo permitan.

\subsection{Programa de Consolidación y Expansión del Mercado}

El Programa de Consolidación y Expansión del Mercado de alimentos va dirigido a empresas españolas que ya cuentan con importador o distribuidor en Canadá. Pretende colaborar con los principales importadores y distribuidores de nuestros productos en la promoción de los mismos a fin de expandir su mercado.

Este plan tiene como antecedentes los planes de promoción de quesos españoles que se desarrollaron en 2015 y 2016. En 2017 se dio el salto a promocionar una mayor gama de productos españoles, integrados en la denominada «despensa española». Se trata fundamentalmente de productos agroalimentarios transformados de gama media-alta. Las especialidades de gama alta como los jamones, tanto serrano como ibérico, se encuentran ya introducidas en las mejores cadenas de supermercados canadienses, y algunos de los quesos españoles como el manchego empiezan a ser conocidos. Las conservas de mariscos y pescados empiezan a adquirir gran prestigio entre el sector de la restauración de las grandes ciudades canadienses.

Hasta la llegada de la COVID-19, la evolución de nuestras ventas de productos transformados estaba siendo muy satisfactoria. Es $D$ 
previsible que esta tendencia se restablezca una vez superada la pandemia.

Durante el periodo 2015-2020, las categorías que más han crecido son el aceite de oliva, los embutidos y las conservas. No obstante, no hay duda de que los productos estrella son el aceite de oliva y las aceitunas. En 2020 se importó aceite de oliva virgen extra español por valor de casi 54 millones de dólares, un $47 \%$ más que el año anterior y 20 veces más que en 2015. En aceitunas, España tiene un papel preponderante como líder del mercado en valor y volumen en distintas presentaciones, desde a granel hasta envasadas en origen.

Con el Programa de Consolidación y Expansión del Mercado se persiguen los siguientes objetivos.

- Ayudar a la diferenciación de la oferta agroalimentaria española en la mente del consumidor:

- Destacando las notas de excelencia, variedad y autenticidad de nuestra oferta agroalimentaria.

- Educando a los consumidores en las características de los productos españoles y en su modo de uso para fomentar su compra y utilización en la vida cotidiana.

- Promoviendo la marca España para potenciar la notoriedad y presencia en el mercado de los distintos productos que componen nuestra oferta en Canadá.

- Aumentar la distribución de nuestros productos, incrementando tanto su presencia en los canales de distribución como su diversificación geográfica:

- Manteniendo y ampliando los contactos con profesionales del sector de la distribución agroalimentaria (importadores, distribuidores) para que España se posicione como un importante proveedor de alimentos en el mercado.

- Educando a profesionales académicos, chefs, dietistas, expertos culinarios, líderes en la industria alimenticia, estudiantes culinarios, para incluir los productos españoles entre las principales tendencias gastronómicas. Este aspecto se desarrolla aún más en el Plan de Gastronomía que se expondrá más adelante.

Para alcanzar los objetivos anteriores, cada año se propone a las empresas participantes una serie de actividades. Se comentan a continuación algunas de las más relevantes que se han desarrollado con cargo al Programa de Consolidación y Expansión del Mercado de alimentos con objeto de ilustrar la estrategia que se viene desplegando.

Para las empresas que participan en el Programa de Consolidación y Expansión del Mercado se desarrolla un conjunto de actividades de promoción específicas en la feria SIAL, que incluye degustaciones, seminarios y difusión de información sobre los distintos productos. El público objetivo de estas iniciativas está compuesto por distribuidores, tiendas de delicatessen y supermercados, periodistas, cocineros y blogueros de reconocido prestigio para que tengan acceso a más información y a degustar los productos del programa. Desde la Oficina Económica y Comercial de España en Toronto se cursan invitaciones a todo este público objetivo y se contacta con la prensa especializada y blogueros.

La participación en La Grande Dégustation de Montreal es otra de las actividades que se han incluido tradicionalmente en este $\square$ 
programa. Aunque es una feria dedicada principalmente al vino, acuden profesionales de la restauración, prensa y público en general. Nuestra presencia permite maridar la promoción de vinos y alimentos de España.

Como novedad en 2019, se organizó un evento claramente orientado a aumentar la distribución de los productos españoles participantes en el programa que se denominó Discover Food and Wine from Spain. Esta iniciativa pretendía que aquellos importadores canadienses que colaboran con empresas españolas comprando sus productos ampliaran su distribución y reforzaran su presencia en el circuito profesional del denominado Food Service o sector HORECA. Para ello se organizó una exposición de los productos de las empresas participantes en el Instituto de Turismo y Hostelería de Quebec.

Los importadores disponían de mesas donde mostrar a los invitados (profesionales y prensa) los productos que traen desde España, ya sea en forma de muestras o integrados en tapas u otras elaboraciones. Además, en la zona central se dedicó un espacio para la degustación de distintas elaboraciones desarrolladas con los productos objeto de exposición. La colaboración con el Instituto de Turismo y Hostelería de Quebec resultó muy exitosa, tanto por el respaldo a la imagen de calidad que supuso cuanto por el aprovechamiento de sus agendas de contacto.

En 2021, la pandemia de la COVID-19 obligó a reconvertir esta acción en una doble dirección. Por un lado, se la dotó de un formato digital a fin de respetar todos los protocolos sanitarios y, por otro, se quiso conectar con la principal preocupación de los profesionales de la restauración y del sector de la alimentación en general en ese momento: su supervivencia financiera. Para ello, el planteamiento de los diferentes eventos digitales intentó resolver las siguientes preguntas: ¿cómo pueden los productos españoles añadir valor a mi menú o a mi oferta?, ¿cómo me ayudan a reforzar y diferenciar mi oferta?, ¿cómo los encajo en mi menú?

Las distintas actividades desarrolladas en el marco de esta acción proporcionaban información para aprender a usar los productos españoles y conectar con la tendencia Take away o Ready to eat. De manera complementaria, se desarrolló una campaña de promoción de los productos del programa dirigida a escritores y blogueros de alimentos. Siguiendo con la estrategia de colaborar con las grandes escuelas de cocina canadiense, la acción Discover Foods from Spain en su formato digital se llevó a cabo en colaboración con el George Brown College, de Toronto.

Para ampliar la distribución geográfica de nuestros productos se organizó, en 2018, un evento de captación de distribuidores en la ciudad de Vancouver. Iba dirigido a aquellas empresas participantes en el programa que solo tienen importadores en Ontario y Quebec. A los participantes se les puso en contacto con profesionales de las provincias de Columbia Británica y Alberta.

Los ejemplos anteriores son una muestra de las distintas iniciativas que se plantean anualmente para alcanzar los objetivos establecidos en el programa. La pandemia ocasionada por la COVID-19 ha obligado a limitar y, en algunos casos, a reconvertir las actividades del programa relacionadas con la organización de eventos, pero estos se retomarán cuando las condiciones sanitarias lo permitan.

Una parte muy relevante del presupuesto del Programa de Consolidación y Expansión del Mercado de alimentos se destina a las promociones punto de venta. De la mano de los $\triangleright$ 
importadores de los productos españoles que participan en el mismo, se realizan degustaciones y otras acciones en los puntos de venta de las principales cadenas de supermercados y tiendas especializadas.

La COVID-19 ha imposibilitado la realización de las degustaciones tradicionales en el punto de venta. Sin embargo, el concepto de acciones de promoción en puntos de venta es más amplio y permite realizar no solo degustaciones, sino también otras actividades o promociones por parte de los importadores. A modo de ejemplo, se abren a los importadores de los productos españoles que participan en el programa, entre otras, las siguientes posibilidades: seminarios online en plataformas de cadenas de supermercados, marketing online a través de redes sociales y anuncios tanto online como en revistas, descuentos en el punto de venta del producto, etc.

\subsection{Programa de Gastronomía}

Con un PIB de 1.441.114 millones de euros y un PIB per cápita de 37.919 euros en 2020 , Canadá lleva años posicionada entre las primeras economías del mundo. Se trata de uno de los países más multiculturales del hemisferio, debido a la gran afluencia de inmigrantes que recibe año tras año. Así, por ejemplo, según el censo de 2016 (el último disponible), el porcentaje de población que vive en Toronto pero que nació fuera de Canadá es del 46,1\%. En el caso de Vancouver, este porcentaje es del $40,8 \%$. En este sentido, durante el primer trimestre de 2020 (antes del inicio de la pandemia) la inmigración representó el 82,3\% del crecimiento de la población.

Si bien la oferta gastronómica de Canadá es amplia y variada, la gastronomía española todavía tiene un largo camino por recorrer, aunque es cada vez más reconocida. Así lo atestigua la constante apertura de nuevos restaurantes de temática española. Solo en Toronto, durante 2018, tres nuevos locales han abierto sus puertas y otros dos en Vancouver y Winnipeg. Además, la lista Canada's 100 Best ha incluido en su edición de 2020 a varios restaurantes españoles: Edulis ( $n .^{\circ}$ 9) y Bar Isabel

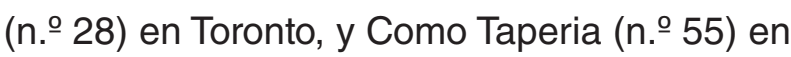
Vancouver.

Los objetivos del Programa de Gastronomía que se desarrolla en el mercado canadiense son los siguientes:

- Conseguir que la gastronomía española adquiera un posicionamiento diferenciado dentro del concepto más general de "gastronomía mediterránea», de forma que la borrosa línea que la separa en la mente del consumidor canadiense de las cocinas italiana o griega quede más definida.

- Dar a conocer la cocina española en su globalidad, mostrando desde los platos más clásicos a las ideas más vanguardistas, a fin de aumentar la visibilidad y variedad de usos de los alimentos de España.

- Transmitir, por último, la tradición y cultura españolas, la importancia de la gastronomía en nuestro día a día. En definitiva, acercar y mejorar la imagen de España a través de la cocina.

Para alcanzar estas metas, el Programa de Gastronomía se dirige al siguiente público objetivo:

- Escuelas de cocina y sus estudiantes. Los futuros chefs que, en pocos años, $D$ 
podrán incorporar nuestros productos y recetas en sus propios restaurantes, de forma que la cocina española vaya ganando posiciones en la variada oferta gastronómica canadiense.

- Chefs canadienses que conocerán de cerca las elaboraciones y los productos españoles y los podrán incorporar a sus cartas.

- Medios de comunicación y redes sociales para que difundan entre sus lectores y seguidores las recetas y experiencias culinarias.

- Público espacialmente interesado en la gastronomía.

La pieza fundamental que sustenta la estrategia que subyace al Programa de Gastronomía es la colaboración con las grandes escuelas de cocina canadienses. Esta se erige en la forma óptima de alcanzar los objetivos asignados a este programa.

La colaboración con el George Brown College ocupa un lugar destacado. El Centre for Hospitality and Culinary Arts es la escuela de cocina de la Universidad de George Brown, con sede en Toronto. Desde su creación en 1967, se ha convertido en una de las principales escuelas de hostelería de Canadá. Cada año se gradúan 1.500 estudiantes. Con una de las tasas de colocación laboral más altas, su cuerpo de antiguos alumnos asciende a 21.000 personas, entre ellos, reconocidos chefs canadienses como Mark McEwan, Christine Cushing, Jason Bangerter y Roger Mooking, algunos de los cuales vuelven a la escuela para impartir talleres y clases a los nuevos estudiantes.

La escuela ofrece programas especializados de cocina extranjera, como el posgrado de Italian Culinary Arts Program o el Advanced French Patisserie Program, así como el
Advanced Wine and Beverage Business Management. Además, habitualmente se lanzan cursos de diferentes especialidades; por ejemplo, se han impartido cursos sobre la cocina mediterránea, con presencia, entre otros, de platos españoles, y también un curso especializado en la cocina española.

Involucrando al George Brown College en las actividades del Programa de Gastronomía, se pretende conectar tanto con los propios estudiantes del centro como con las personas incluidas en su base de datos (reconocidos chefs, restaurantes, dietistas, medios de comunicación y otros profesionales del sector).

Cada año se acuerda con este centro un conjunto de actividades a realizar en común, entre las que destacan:

- La organización de talleres culinarios de gastronomía española. Enfocados a los estudiantes de la escuela, se enseña cómo realizar platos típicos españoles y se acompañan de microseminarios de maridaje de vinos españoles. Se suele invitar a algunas personas de los medios de comunicación para multiplicar el mensaje y lograr un mayor alcance en la comunicación.

- Cenas con medios de comunicación y expertos de la industria en las que se invita para la ocasión a un chef español de reconocido prestigio. Se aprovechan estas cenas para crear platos de clara inspiración española, pero sin anclarse en los más típicos, y así acercar la cocina contemporánea española al público canadiense.

- Concursos culinarios con productos españoles en los que participan los estudiantes del centro, donde el jurado está formado por chefs expertos y $\triangleright$ 
periodistas. El objetivo de esta actividad es que los estudiantes de la escuela profundicen en sus conocimientos sobre nuestra gastronomía y sean capaces de crear su propio plato de cocina española, de forma que estos conceptos vayan incorporándose a su acervo educativo.

- Clases magistrales de cocina española abiertas al público interesado en la gastronomía, blogueros y periodistas, cuya finalidad es promocionar los productos y las recetas españolas entre personas influyentes en el mundo gastronómico e iniciar o ampliar la conversación sobre alimentos españoles en las redes sociales.

Es intención del Programa de Gastronomía ir ampliando estos esquemas de colaboración, incorporándolos a otras escuelas canadienses de cocina de reconocido prestigio. En el punto de mira están, entre otras, las siguientes escuelas: L'Institut de tourisme et d'hôtellerie du Québec y el Canadian Food and Wine Institute de Niagara College.

Aparte de las iniciativas que se acometen en colaboración con las escuelas de cocina canadienses, se organiza con cargo a este programa la participación en el Día Mundial de la Tapa. Se trata de una suerte de mercado culinario donde los chefs de los principales restaurantes de Toronto crean tapas y las ofrecen a los asistentes. El perfil de los asistentes es el de público general con un marcado gusto por la gastronomía y la cocina gourmet. No hay que olvidar que los restaurantes que participan no son necesariamente españoles, por lo que los chefs necesitan estudiar e investigar nuestra gastronomía para poder ofrecer tapas innovadoras sin perder la esencia española. De esta forma, ellos mismos se convierten en un objetivo de esta acción.
Señalar, por último, que con cargo al programa también se está presente en los grandes eventos del sector a través de la figura del patrocinio. Así, por ejemplo, Alimentos y Vinos de España será el principal patrocinador del Ambition Nutrition Symposium. Este simposio reúne a profesionales académicos, dietistas, expertos culinarios y líderes de la industria gastronómica en torno a temas de actualidad dentro de la industria alimentaria.

El principal objetivo de patrocinar este evento no solo es poner de manifiesto la calidad de la gastronomía española, sino que los profesionales asistentes entiendan que los productos españoles son esenciales para una dieta saludable y equilibrada y los incluyan en sus recetas, estudios y recomendaciones.

\subsection{Programa de Planes Sectoriales}

\subsubsection{Plan de Promoción de Vinos de España}

Canadá es un mercado en expansión para las exportaciones europeas de vinos, especialmente después de la entrada en vigor del Acuerdo Económico y Comercial Global, conocido como CETA por sus siglas en inglés. Asimismo, la población del país crece perceptiblemente año tras año con el aumento de la inmigración, y cada vez se observa una mayor sofisticación en sus conocimientos vitivinícolas y gustos culinarios, algo que se adapta muy bien a la oferta española.

La oferta de vino en Canadá proviene mayoritariamente de la importación, que representa en torno al $60 \%$ del mercado, ya que la producción vitivinícola canadiense no alcanza para abastecer la demanda. Así, Canadá se posiciona como el $6 .$. mayor importador de vino a $\triangleright$ 
nivel mundial, con una importación total por valor de 2.645.724 miles de CAD ${ }^{1}$. En cuanto a las importaciones de vino español, en 2020 alcanzaron los 167.386 miles de CAD continuando con la tendencia creciente en los últimos años, tanto en valor como en volumen. Las importaciones de Canadá de vino español han aumentado muy por encima de las importaciones generales de vino. De hecho, España se sitúa hoy en día entre los países exportadores de vino que más ha crecido significativamente en los últimos años, precedido únicamente por Francia, Italia, Estados Unidos y Australia. No obstante, aunque otros países como Francia e Italia continúan ganando terreno en el mercado canadiense, España sigue situándose entre los países con mayor crecimiento de importaciones, seguido únicamente por Nueva Zelanda y Australia.

En el Cuadro 2 se muestran los datos más detallados de la evolución de las importaciones de vino de los países líderes en el sector.

El mercado canadiense presenta peculiaridades que lo hacen muy diferente a otros, principalmente debido a que existe un organismo responsable de la importación, distribución y comercialización de bebidas alcohólicas en prácticamente todas las provincias de Canadá (exceptuando la provincia de Alberta, donde se privatizó parcialmente el sistema de distribución), genéricamente denominados liquor boards.

Pese a que las ventas de vino en Canadá no han dejado de crecer en los últimos años, es un mercado relativamente joven y la cultura del vino para el consumidor canadiense medio aún es nueva. No es un elemento básico en la dieta ni habitual en las comidas, como en los países mediterráneos, sino que se asocia a un

1 Dólares canadienses. acontecimiento especial o, al menos, a acontecimientos que escapen de la rutina diaria. Todo ello apunta a que existe todavía un gran potencial de crecimiento.

Las importaciones de vino español en Canadá han aumentado un 107,59\% en valor en el periodo de 2010 a 2020. España es el 5.ㅇ país suministrador de vino a Canadá, con una cuota de mercado del $6 \%$ en 2020. Sin embargo, el conocimiento por parte de los consumidores canadienses del producto español es aún insuficiente, si bien en mercados como el de Ontario y Quebec algunos consumidores ya son capaces de reconocer diferentes tipos de uva española, como tempranillo o albariño. Asimismo la buena relación calidad-precio de los vinos españoles es valorada muy positivamente por los consumidores canadienses que suelen adquirir regularmente vino español.

De las consideraciones anteriores se desprende que los vinos españoles se encuentran en una buena posición para aprovechar las oportunidades que presenta el mercado canadiense, apoyándose en algunos de sus valores diferenciales como la buena relación calidad-precio, la variedad de referencias y los aspectos culturales, turísticos y gastronómicos que envuelven el mundo del vino en España.

El Plan de Promoción de Vinos de España en el mercado canadiense pretende contribuir a posicionar a España como uno de los principales países productores de vino y a colocar sus caldos en un segmento de valor superior al actual. Para ello se establecen los siguientes objetivos:

- Apoyar a las bodegas españolas en su estrategia de acceso al mercado canadiense.

- Fomentar la presencia de los vinos españoles en los canales de distribución $\triangleright$ 
PLAN INTEGRADO DE PROMOCIÓN DE ALIMENTOS Y VINOS EN EL MERCADO CANADIENSE

CUADRO 2

EVOLUCIÓN DEL LOS 10 PRINCIPALES PAÍSES SUMINISTRADORES DE VINO A CANADÁ PARA EL PERIODO 2010-2020

(En miles de dólares canadienses)

\begin{tabular}{|c|c|c|c|c|c|c|c|c|c|c|c|c|}
\hline País & 2010 & 2011 & 2012 & 2013 & 2014 & 2015 & 2016 & 2017 & 2018 & 2019 & 2020 & $\begin{array}{l}2010- \\
2020\end{array}$ \\
\hline Francia .... & 385.357 & 433.994 & 437.662 & 468.915 & 442.989 & 465.301 & 486.236 & 526.420 & 566.919 & 587.898 & 602.372 & $56,32 \%$ \\
\hline Estados Unidos ...... & 276.644 & 325.936 & 374.358 & 430.512 & 471.173 & 509.373 & 503.930 & 513.057 & 535.904 & 520.367 & 568.089 & $105,35 \%$ \\
\hline Italia ............................. & 349.754 & 380.344 & 394.588 & 415.441 & 425.234 & 462.093 & 483.452 & 515.254 & 540.014 & 553.195 & 552.939 & $58,09 \%$ \\
\hline Australia ... & 257.796 & 250.267 & 237.703 & 225.251 & 225.228 & 234.903 & 221.017 & 216.613 & 242.708 & 223.376 & 209.669 & $-18,67 \%$ \\
\hline España & 80.632 & 98.875 & 101.559 & 109.678 & 116.469 & 125.897 & 131.679 & 151.511 & 163.036 & 162.891 & 167.386 & $107,59 \%$ \\
\hline Nueva Zelanda ....... & 50.325 & 61.074 & 70.959 & 77.692 & 90.619 & 100.616 & 111.628 & 117.207 & 124.820 & 127.688 & 128.235 & $154,81 \%$ \\
\hline Chile ......................... & 99.853 & 99.251 & 98.875 & 99.242 & 107.403 & 118.629 & 134.718 & 124.483 & 123.640 & 123.501 & 124.750 & $24,93 \%$ \\
\hline Argentina .......... & 102.955 & 99.023 & 106.258 & 102.594 & 107.697 & 115.961 & 105.894 & 100.456 & 103.186 & 105.581 & 106.760 & $3,70 \%$ \\
\hline Portugal ...... & 50.189 & 51.438 & 49.166 & 54.836 & 53.369 & 58.052 & 60.395 & 65.448 & 72.592 & 72.593 & 77.292 & $54,00 \%$ \\
\hline Sudáfrica .... & 47.341 & 44.094 & 49.608 & 47.571 & 49.449 & 48.626 & 52.386 & 52.656 & 49.780 & 44.349 & 41.541 & $-12,25 \%$ \\
\hline Subtotal. & 1.700 .847 & 1.844 .296 & 1.920 .736 & 2.031 .732 & 2.089 .629 & 2.239 .451 & 2.291.335 & 2.383.104 & 2.522 .599 & 2.521 .439 & 2.579 .032 & $51,63 \%$ \\
\hline Otros .... & 48.920 & 50.427 & 53.169 & 54.051 & 54.129 & 57.385 & 58.212 & 63.458 & 63.952 & 64.216 & 66.692 & $36,33 \%$ \\
\hline Total .. & 1.749 .767 & 1.894 .724 & 1.973 .906 & 2.085 .783 & 2.143.758 & 2.296 .836 & 2.349 .546 & 2.446 .563 & 2.586 .550 & 2.585 .656 & 2.645 .724 & $51,20 \%$ \\
\hline
\end{tabular}

de los monopolios (liquor boards) provinciales.

- Potenciar la imagen de España como uno de los países productores de vino de mayor calidad.

- Aumentando el nivel de visibilidad de los vinos españoles en prensa y redes sociales.

- Trabajando con prescriptores, escuelas de vino y hostelería para educar a los consumidores.

- Colaborando con el canal HORECA en actividades de promoción.

Se trata, en definitiva, de educar a los consumidores y profesionales de Canadá en las fortalezas de los vinos españoles (tipos de vinos, varietales, regiones o denominaciones de origen) de forma que sean capaces de identificarlos y demandarlos en el mercado.

El mercado canadiense exige de actuaciones específicas para cada una de las provincias que se han establecido como zonas prioritarias de actuación, debido a las diferencias existentes entre el público objetivo y la normativa de los liquor boards de cada una de ellas.

En un contexto vitivinícola cada vez más complicado y competitivo, la calidad es indispensable, pero no es para nada suficiente. Por ello resulta preceptivo utilizar todas las herramientas de promoción a nuestro alcance con el fin de adaptar nuestras acciones a las particularidades de los diferentes mercados canadienses, a los parámetros de los diversos monopolios, a las propias expectativas de los expertos y profesionales del sector, así como de la prensa especializada, y llegar, finalmente, a los consumidores de vino. La estrategia de promoción que subyace al Plan de Vinos de España cuenta con las siguientes herramientas:

- Campañas de publicidad en medios digitales e impresos para trasladar los mensajes a los consumidores y a los prescriptores de opinión a través de medios especializados. Se impulsa la publicación de contenidos, junto a la inserción ocasional de anuncios $\triangleright$ 
publicitarios. La colaboración con medios no se limita a revistas online y offline tradicionales, sino que incluye la colaboración con canales relevantes de líderes de opinión en el ámbito del vino, gastronomía y estilo de vida.

- Promoción en redes sociales y portales web. La promoción online se ha convertido en una pieza fundamental en el mercado canadiense, siendo las redes sociales uno de los canales esenciales. Se utiliza el portal www.foodswinesfromspain.com como web de referencia para la promoción de los vinos de España. Apoyándose en dicho portal, el Plan de Vinos despliega una gran actividad en redes sociales, mediante:

- La gestión de los perfiles específicos existentes en las redes sociales Instagram, Facebook y Twitter.

- La publicación de contenido en las redes sociales, que incluye información sobre actividades de la campaña de comunicación, sobre los vinos de calidad españoles, cultura y estilo de vida de España, creando igualmente vínculos entre la imagen de los vinos de España y la cultura canadiense, especialmente asociada a fechas 0 eventos relevantes. También se colabora con líderes de opinión que puedan crear contenidos específicos.

- Misiones inversas. Se organizan, con cargo al Plan de Vinos, misiones a España tanto de prescriptores de opinión como de personalidades relevantes de los distintos monopolios provinciales, a los que se invita a visitar las bodegas de un área geográfica de España.

- Oficina de Información y Relaciones Públicas. Sirve de punto de contacto para asistir a periodistas especializados, escritores, blogueros y otros prescriptores de opinión. Permite ejecutar un programa dinámico de comunicación.

- Colaboraciones con los monopolios provinciales. El objetivo que se persigue es doble: por un lado, se pretende aumentar la presencia de los vinos españoles en sus canales de distribución; $y$, por otro, incrementar de la mano de los monopolios el conocimiento y la visibilidad de los vinos españoles ante el consumidor canadiense. Las acciones que se acometen van desde la organización conjunta de seminarios para empleados de las tiendas, consultores de vino y público en general hasta la promoción en el punto de venta. Los seminarios y catas dirigidos a los consultores y profesionales de los monopolios de bebidas alcohólicas les proporcionan un mayor conocimiento de los vinos españoles para que puedan actuar como prescriptores en las tiendas. Otra de las actividades destacables es la promoción que se realiza en la tienda del LCBO (monopolio de Ontario) especializada en vinos españoles. Esta tienda se abrió al público en septiembre de 2015 como parte del programa Products of the World del LCBO, que incluye tiendas especializadas en vinos de otros países tales como Portugal, Grecia, Nueva Zelanda y Argentina.

- Colaboración con las escuelas de vino y hostelería. La educación, más aún en un mercado como el canadiense, en el que el conocimiento sobre el vino español es escaso, es un pilar fundamental de la campaña de comunicación. Es una herramienta con gran $\triangleright$ 
capacidad multiplicadora para transmitir el mensaje de calidad y diversidad de los vinos de España. Además, permite que los distribuidores mejoren sus resultados a través de la capacitación de sus comerciales. El Plan de Promoción de Vinos de España colabora con las dos principales escuelas de cocina de Canadá: el Centre for Hospitality and Culinary Arts de la Universidad de George Brown, afincado en Toronto, y el Institut de tourisme et d'hôtellerie (ITHQ), ubicado en Montreal. La colaboración con ambas escuelas comprende el patrocinio de simposios de vino, la realización de catas para medios y prescriptores de opinión, la realización de clases magistrales sobre las diferentes regiones vitivinícolas españolas para medios profesionales y estudiantes de las escuelas, clases de maridaje de vinos españoles con diferentes comidas populares de todo el mundo, y cursos de formación y acreditación dirigidos a estudiantes y profesionales del sector. Merece ser también destacada la colaboración con la escuela Independent Wine Education Guild (IWEG), que es la única en la provincia de Ontario que certifica y da el diploma en Wine \& Spirit Education Trust (WSET), la certificación educativa de vino con más alto estándar en Canadá.

- Participación en ferias. El Plan de Promoción de Vinos de España contempla la participación en distintos eventos feriales, entre los que destacan Toronto Gourmet Show, Toronto Wine Week, Vancouver International Wine Festival y Top Drop.

\subsubsection{Campaña de Promoción de Cítricos}

Debido a sus condiciones climatológicas, Canadá es un país imposibilitado para producir frutos cítricos. Durante sus largos inviernos, y por cuanto a los productos hortofrutícolas básicos, este mercado es abastecido eficientemente desde sus suministradores tradicionales ubicados en los estados de Florida y Texas, y también desde México.

El mercado canadiense es un mercado sofisticado en cuanto a la variedad de su demanda de productos frescos. La estacionalidad de estos productos da lugar a nichos de mercado muy marcados. Tal es el caso de los cítricos, y, dentro de ellos, de las clementinas y las naranjas tempranas.

Las clementinas son consideradas en Canadá como una especialidad de temporada que coincide con las fiestas de fin de año. No obstante, existe un reducido consumo en otras épocas del año, atendidas por productores del hemisferio sur. Los suministradores de las clementinas en la temporada de invierno, la más importante del año (durante los meses de octubre, noviembre y diciembre), son, fundamentalmente, Marruecos y España. A partir de octubre de cada año existe una carrera por ser el primer suministrador y una subsecuente guerra de precios por el mercado canadiense entre los productores de España y Marruecos. Esta competencia es muy añeja y se remonta a casi treinta años, cuando Marruecos crea la contramarca «MAROC», que sigue estando bastante establecida.

Tradicionalmente, el mercado canadiense de naranjas de invierno (enero a marzo) se abastece por los suministradores naturales radicados en los estados de Florida y California, y de Texas en menor medida. Sin embargo, debido a los trastornos climáticos que $D$ 
empiezan a ser muy frecuentes, como heladas en Florida y sequías o inundaciones en California, empiezan a aparecer naranjas de origen europeo en los supermercados canadienses.

Del análisis de la estructura de suministro de clementinas al mercado de invierno canadiense (Marruecos vs. España) se desprende que se trata de un mercado estable (con las clásicas oscilaciones a través de los años debidas al volumen de la oferta y al crecimiento de una demanda modestamente al alza), donde el precio y la oportunidad de mercado son los factores que más influyen en el consumidor final.

En esta competencia por el mercado de invierno de clementinas, Marruecos ha tomado una decidida delantera en los últimos años, seguramente apoyado en sus costos de producción más flexibles, conquistando cuotas de mercado a costa de la clementina española. Los cuadros de Statiscs Canada que se muestran a continuación dan idea de la evolución de las ventas de los dos principales suministradores de clementinas al mercado canadiense. Sin embargo, y debido a que en 2016 se produjo un cambio de nomenclatura (segregando las importaciones de clementina de las demás mandarinas), se muestra el desarrollo de esta competencia entre Marruecos y España en dos cuadros distintos.

En el Cuadro 3, sobre las importaciones canadienses de mandarinas, clementinas y wilkings, se incluye, además de los suministradores de invierno (fundamentalmente de clementina), a los suministradores de mandarina (incluidas clementinas) de verano (Cono Sur). Sin embargo, en el Cuadro 4 se ve perfectamente la competencia de los dos suministradores de clementina, exclusivamente.

Como se puede apreciar en este último cuadro, con las cifras desagregadas (exclusivamente clementinas) del valor de la importación en Canadá, Marruecos es el principal suministrador del mercado canadiense con diferencia, $\triangleright$

CUADRO 3

PRINCIPALES PAÍSES EXPORTADORES DE MANDARINAS, CLEMENTINAS, WILKINGS E HÍBRIDOS SIMILARES

A CANADÁ (HS - 080520) EN EL PERIODO 2010-2016*

(En miles de dólares canadienses)

\begin{tabular}{|c|c|c|c|c|c|c|c|c|}
\hline & País & 2010 & 2011 & 2012 & 2013 & 2014 & 2015 & 2016 \\
\hline 1 & Marruecos & 82.328 & 68.088 & 63.729 & 59.728 & 55.188 & 108.935 & 121.834 \\
\hline 2 & Estados Unidos & 31.367 & 32.334 & 26.830 & 32.124 & 33.255 & 41.491 & 36.275 \\
\hline 3 & China & 23.611 & 24.972 & 25.099 & 22.943 & 20.800 & 23.765 & 25.145 \\
\hline 4 & España & 6.746 & 11.204 & 16.321 & 11.835 & 29.328 & 26.738 & 24.687 \\
\hline 5 & 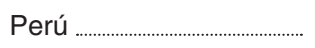 & 5.820 & 9.410 & 13.091 & 13.034 & 16.800 & 16.084 & 19.240 \\
\hline 6 & Sudáfrica & 5.050 & 6.796 & 9.148 & 11.360 & 12.923 & 12.385 & 12.952 \\
\hline 7 & Israel & 3.858 & 2.327 & 8.116 & 8.140 & 10.011 & 13.193 & 10.320 \\
\hline 8 & Chile & 3.628 & 3.964 & 5.101 & 4.646 & 6.346 & 8.183 & 7.818 \\
\hline 9 & Argentina & 1.697 & 3.342 & 3.860 & 3.647 & 5.173 & 6.170 & 5.642 \\
\hline 10 & 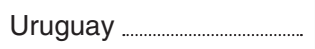 & 1.462 & 1.725 & 1.477 & 2.687 & 3.437 & 2.166 & 2.821 \\
\hline 11 & Japón & 1.408 & 2.263 & 2.470 & 3.003 & 3.969 & 2.903 & 2.241 \\
\hline 12 & Chipre & 1.343 & 732 & 1.200 & 909 & 820 & 655 & 1.453 \\
\hline 13 & Australia & 1.281 & 804 & 762 & 948 & 607 & 1.560 & 1.359 \\
\hline 14 & Corea del sur & 730 & 528 & 700 & 845 & 867 & 1.185 & 1.012 \\
\hline \multirow[t]{2}{*}{15} & Pakistán .......................................... & 258 & 410 & 431 & 318 & 454 & 450 & 339 \\
\hline & Total . & 171.176 & 170.161 & 179.749 & 177.437 & 200.618 & 266.844 & 273.878 \\
\hline
\end{tabular}


CUADRO 4

PRINCIPALES PAÍSES EXPORTADORES DE CLEMENTINAS A CANADÁ (HS - 080522) EN EL PERIODO 2017-2020*

(En miles de dólares canadienses)

\begin{tabular}{|c|c|c|c|c|c|}
\hline & País & 2017 & 2018 & 2019 & 2020 \\
\hline 1 & Marruecos & 122.783 & 96.214 & 92.852 & 106.246 \\
\hline 2 & España & 17.002 & 31.101 & 31.953 & 32.116 \\
\hline 3 & Sudáfrica & 7.603 & 11.543 & 11.198 & 17.550 \\
\hline 4 & Estados Unidos & 7.444 & 5.977 & 12.090 & 13.620 \\
\hline 5 & 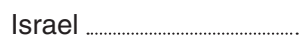 & 8.515 & 4.801 & 6.428 & 7.034 \\
\hline 6 & Uruguay & 1.468 & 1.598 & 2.540 & 2.742 \\
\hline 7 & Perú & 585 & 849 & 1.379 & 2.581 \\
\hline 8 & Argentina & 3.402 & 2.545 & 4.401 & 1.559 \\
\hline 9 & 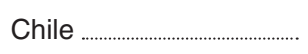 & 945 & 1.938 & 1.004 & 939 \\
\hline 10 & Italia & 29 & - & 52 & 91 \\
\hline 11 & Portugal $\ldots \ldots$ & 66 & 4 & 23 & 29 \\
\hline 12 & Túnez …........................................ & 11 & 76 & 1 & 14 \\
\hline 13 & Brasil ........................................... & 65 & - & 58 & 5 \\
\hline 14 & México …………........................... & - & 24 & - & 5 \\
\hline \multirow[t]{2}{*}{15} & Argelia & - & 6 & - & 2 \\
\hline & Total $\ldots \ldots \ldots \ldots \ldots \ldots \ldots \ldots \ldots \ldots \ldots$ & 170.019 & 156.912 & 164.026 & 184.535 \\
\hline
\end{tabular}

con una cuota del 57,6\% del mercado en 2020. Para ese mismo año, España aportó solamente el $17,5 \%$ del mercado total de clementinas.

Del análisis anterior se desprende que España es un suministrador consolidado de clementinas al mercado canadiense. No obstante, existe una brecha considerable entre nuestras ventas y las de nuestro competidor principal: Marruecos. Cerrar esta brecha de mercado con Marruecos es el fin último de la campaña de promoción de clementinas incluida en el Plan de Promoción de Cítricos. Este plan de promoción es fruto de la colaboración de ICEX con el Ministerio de Agricultura, Pesca y Alimentación.

La campaña de promoción de clementinas que se desarrolla en el mercado canadiense tiene dos objetivos:

- Aumentar las ventas de la clementina española en las cadenas de supermercados, donde se concentra el $80 \%$ de las ventas de clementinas durante el periodo álgido de venta (del 1 de noviembre al 31 de diciembre).

- Recuperar la identidad española de la clementina en Canadá, mostrando un posicionamiento diferenciado frente a la marroquí. No se trata de promover el consumo de clementinas, sino de diferenciar nuestra oferta frente a la de nuestro competidor.

Para alcanzar estos objetivos, la campaña de promoción establece claramente la identidad del producto español de forma que sea fácil de identificar por el consumidor final en el punto de venta. La clementina española se diferencia del producto rival merced a una creatividad moderna y colorida con una fuerte identidad visual.

La estrategia de comunicación descansa sobre dos pilares: 
- Una campaña de publicidad en medios convencionales y virtuales que traslada al consumidor el nuevo posicionamiento elegido, utilizando especialmente aquellos medios próximos a las cadenas de supermercados.

- Acciones de promoción punto de venta en supermercados para intentar incidir en la decisión del consumidor final en el punto de venta y así fomentar las ventas en los lineales.

El mercado de invierno de naranjas en Canadá es bastante competido. Participan los grandes productores de Estados Unidos, particularmente Florida, Texas y California, en distintas franjas temporales de abastecimiento. Sin embargo, y debido a una serie de problemas climatológicos que vienen aconteciendo en el subcontinente norteamericano motivados por el cambio climático, se han creado huecos y ventanas de oportunidad para productores extracontinentales como España.

Mientras que en las clementinas, España es un suministrador reconocido y consolidado que participa consistentemente desde hace muchos años, en el caso de nuestras naranjas el suministro es apenas emergente y errático, debido a que se basa en el aprovechamiento del mercado desatendido por heladas en Florida o bien inundaciones en California (Cuadro 5).

Sin embargo, y cada vez con mayor frecuencia, vemos naranjas españolas en los supermercados canadienses, compitiendo con las estadounidenses y mostrando incluso diferencias sustanciales de calidad, tamaño y sabor dulce. Los importadores canadienses ya tienen en cuenta el producto español ante la menor sospecha de trastorno climatológico entre sus suministradores tradicionales en el sur de EE. UU.

Recogiendo las consideraciones anteriores, el Plan de Cítricos desarrolla una campaña $\triangleright$

CUADRO 5

PRINCIPALES PAÍSES EXPORTADORES DE NARANJAS A CANADÁ (HS - 080510) EN EL PERIODO 2010-2020* (En miles de dólares canadienses)

\begin{tabular}{|c|c|c|c|c|c|c|c|c|c|c|c|c|}
\hline & País & 2010 & 2011 & 2012 & 2013 & 2014 & 2015 & 2016 & 2017 & 2018 & 2019 & 2020 \\
\hline 1 & Estados Unidos ....... & 136.539 & 127.485 & 123.024 & 132.302 & 141.808 & 154.792 & 176.024 & 162.506 & 156.506 & 123.655 & 153.991 \\
\hline 2 & Sudáfrica …....................... & 27.607 & 32.229 & 34.802 & 37.909 & 36.214 & 42.528 & 37.275 & 42.514 & 47.717 & 35.968 & 46.510 \\
\hline 3 & España & 1.138 & 954 & 2.598 & 2.752 & 24.757 & 14.625 & 7.329 & 19.811 & 38.134 & 38.135 & 29.037 \\
\hline 4 & Marruecos & 235 & 184 & 476 & 913 & 3.035 & 5.402 & 843 & 8.007 & 12.687 & 18.887 & 14.253 \\
\hline 5 & Australia & 5.176 & 4.141 & 4.050 & 4.602 & 2.954 & 3.976 & 7.913 & 8.061 & 9.254 & 6.435 & 8.231 \\
\hline 6 & Chile …………....................... & 4.338 & 5.186 & 4.898 & 6.096 & 3.545 & 3.869 & 4.174 & 4.551 & 2.975 & 5.578 & 3.905 \\
\hline 7 & Argentina & 1.168 & 909 & 851 & 284 & 310 & 433 & 1.645 & 2.233 & 795 & 1.462 & 2.564 \\
\hline 8 & Perú & 657 & 131 & 144 & 91 & 100 & 63 & 214 & 106 & 510 & 229 & 2.302 \\
\hline 9 & Egipto ........... & 105 & 39 & 16 & 30 & 46 & 126 & 837 & 1.148 & 3.266 & 982 & 1.767 \\
\hline 10 & México & 203 & 206 & 280 & 367 & 645 & 927 & 876 & 1.431 & 1.477 & 1.127 & 1.239 \\
\hline 11 & Uruguay ............................... & 604 & 478 & 252 & 623 & 705 & 330 & 1.726 & 1.396 & 1.165 & 1.106 & 1.159 \\
\hline 12 & China .. & 515 & 546 & 428 & 333 & 378 & 421 & 88 & 98 & 449 & 323 & 822 \\
\hline 13 & Zimbabue & 246 & 67 & - & - & 25 & 355 & 58 & - & - & 82 & 680 \\
\hline 14 & Italia ..... & 422 & 614 & 403 & 449 & 819 & 493 & 731 & 89 & 372 & 615 & 482 \\
\hline \multirow[t]{2}{*}{15} & Israel .................................... & 105 & 266 & 133 & 53 & 197 & 73 & 6 & 64 & 149 & 44 & 220 \\
\hline & Total ... & 179.432 & 173.790 & 172.650 & 187.419 & 216.565 & 228.867 & 240.646 & 253.369 & 276.977 & 235.768 & 268.044 \\
\hline
\end{tabular}


de apoyo a nuestras naranjas tempranas (navelinas, fundamentalmente, pero también Valencia Late) para intentar consolidar su posición de suministrador alternativo, debido a que los trastornos climatológicos empiezan a configurarse como fenómenos recurrentes en el continente norteamericano.

La campaña de promoción de las naranjas tempranas se estructura como un ejercicio de relaciones públicas dirigido al comercio con dos objetivos fundamentales:

- Consolidar a los productores españoles como suministradores alternativos de la distribución canadiense.

- Resaltar la calidad y presentación de las naranjas españolas, familiarizando a los distribuidores canadienses con su época de suministro.

Todas las acciones de relaciones públicas que se desarrollan con cargo a la campaña van dirigidas a los importadores, distribuidores y compradores de cítricos de cadenas de supermercados.

\subsubsection{Campaña de Promoción del Caqui}

España es líder mundial en exportación de caqui y goza de una posición cada vez más sólida en Canadá. Por primera vez en 2020, España se posicionaba como el principal exportador de caqui a Canadá, con un crecimiento del $30 \%$ en sus ventas respecto al año anterior y alcanzando una cuota de mercado del $42 \%$. Así, España es de los países que más ha crecido en sus suministros de caqui a Canadá, con un $188 \%$ en los últimos cinco años.

Si bien las cifras de exportaciones no presentan un crecimiento sostenido debido a las variaciones en cuanto a la producción en origen y la variabilidad que presenta, en general, la producción agrícola, y especialmente un producto tan localizado en un área relativamente pequeña implica que, ante fenómenos climatológicos y fitosanitarios, normalmente se ve expuesta una gran parte de la producción.

El Plan de Promoción del Caqui se realiza conjuntamente con el Consejo Regulador de la Denominación de Origen Protegida Kaki Ribera del Xúquer, con sede en Valencia. Todas las actividades de promoción de caqui se llevan a cabo siempre bajo la marca de PersiMon®, la marca comercial registrada por parte del Consejo Regulador.

Teniendo en cuenta que la cuota de mercado del caqui español en Canadá es del $28 \%$, se han marcado dos objetivos para el Plan de Promoción:

- Reforzar la identidad y visibilidad del Kaki PersiMon® en el mercado canadiense. El objetivo sigue siendo que el consumidor canadiense se familiarice con él, concretamente con la variedad rojo brillante de la Ribera del Xúquer, que se distingue del resto por su tamaño y por estar listo para comer desde el momento de adquisición del producto.

- Reforzar las ventas del Kaki PersiMon® y consolidar los niveles de cuota de mercado frente a los principales países competidores. Se pretende incrementar las crecientes cifras de venta de esta variedad de caqui en Canadá y mantener e incrementar la cuota de mercado de España y poder erosionar al primer exportador, EE. UU.

Para alcanzar estos objetivos, la estrategia se apoya en dos grandes líneas de actuación: un ejercicio de comunicación, fundamentalmente en medios digitales; y un conjunto de actividades de promoción consistentes en promociones punto de venta, participación en ferias, actividades con la restauración y colaboración con entidades de prestigio local. 
